\title{
REVITALISASI PARTISIPASI MASYARAKAT DALAM GERAKAN LITERASI NASIONAL: STUDI PADA PROGRAM KAMPUNG LITERASI
}

\section{Layli Hidayah, Ganjar Setyo Widodo, Sueb}

Fakultas Keguruan dan Ilmu Pendidikan, Universitas Islam Malang Indonesia Jurusan Bahasa dan Sastra Inggris, Universitas Negeri Surabaya

laylihidayah@gmail.com

\begin{abstract}
Abstrak
Implementasi program literasi yang dicanangkan oleh pemerintah, tidak semua pemangku kebijakan memahami benar budaya literasi. Selain itu kurangnya peran serta masyarakat dalam menyukseskan program literasi, mengakibatkan rendahnya pemahaman bahwa literasi hanya terbatas tentang membaca dan menulis saja. Hal ini dibuktikan dari tidak semua Taman Baca Masyarakat (TBM) ramai pengunjung. Penelitian ini merupakan penelitian deskriptif kualitatif yang bertujuan untuk menjelaskan persepsi dan peran masyarakat dalam menyukseskan Gerakan Literasi Nasional (GLN) melalui budaya literasi di masyarakat, serta memberikan rekomendasi tentang peranan masyarakat terhadap revitalisasi dalam menyukseskan Gerakan Literasi Nasional. Berdasarkan hasil penelitian ditemukan bahwa perlunya peran serta pemerintah desa dalam optimalisasi program literasi.
\end{abstract}

Kata Kunci: revitalisasi, gerakan literasi nasional, desa literasi

\begin{abstract}
In the implementation of literacy practice launched by the government, not all policy makers understand the culture of literacy. Due to the lack of understanding and participation by the community in the success of the literacy program, it is only considered as only limited to reading and writing. It has been proven from the fact in the society that not all community library are crowded by visitors. This is a qualitative descriptive study which is intnended to elaborate the roles and participation of community in literacy village. Based on the results of the research, it was found that the need for village government participation in the optimization of literacy programs.
\end{abstract}

Keywords: revitalization, national literacy movement, literacy village 


\section{PENDAHULUAN}

Kemampuan berliterasi merupakan salah satu kebutuhan paling penting bagi individu agar dapat berkompetisi di Abad ke-21. Literasi tidak hanya membaca dan menulis, melainkan berkaitan dengan tuntutan untuk memahami informasi secara kritis dan analitis (UNESCO, 2003). Akan tetapi, pembelajaran di sekolah saat ini belum mampu mewujudkan hal tersebut. Sebagaimana dipaparkan dalam laporan Programme for International Student Assessment (PISA) pada tahun 2009, kemampuan siswa Indonesia berada pada peringkat ke57 (dari 65 negara yang berpartisipasi) dengan skor di bawah rata-rata OECD yakni 493. Sementara laporan PISA pada tahun 2012 juga menunjukkan kondisi yang tidak berbeda (OECD, 2014). Adanya ketimpangan ini menunjukkan bahwa adanya ketidaksinkronan dalam perencanaan serta implementasi pendidikan di Indonesia yang berakibat rendahnya motivasi belajar di antara masyarakat Indonesia, terutama di pendidikan dasar yang menjadi fondasi dalam menanamkan kemampuan berliterasi di jenjang selanjutnya, di mana salah satu indikator keberhasilannya ada pada berkarakter belajar sepanjang hayat (Permendikbud No. 23/2013 tentang standar minimum pendidikan dasar).

Pemerintah melalui Kementerian Pendidikan dan Kebudayaan (Kemdikbud) menggalakkan satu program gerakan literasi nasional (GLN), di mana salah satu contohnya adalah gerakan literasi sekolah (GLS) yang melibatkan semua pemangku kepentingan di bidang pendidikan, mulai dari tingkat pusat, provinsi,kabupaten/kota, hingga satuan pendidikan. GLN dikembangkan berdasarkan sembilan agenda prioritas pemerintah (dikenal dengan istilah Nawacita) yang terkait dengan tugas dan fungsi Kemendikbud, khususnya Nawacita nomor (5) meningkatkan kualitas hidup manusia dan masyarakat Indonesia; (6) meningkatkan produktivitas rakyat dan daya saing di pasar internasional sehingga bangsa Indonesia bisa maju danbangkit bersama bangsabangsa Asia lainnya; (8) melakukan revolusi karakterbangsa Rahayu \& Dahlan (2016); Wandasari (2017); Teguh (2017); (9) memperteguh kebinekaan dan memperkuat restorasi sosial Indonesia.Empat butir Nawacita tersebut terkait erat bagaimana membangun komponen sumber daya manusia berkualitas, produktif, dan berdaya saing, berkarakter, serta nasionalis melalui kegiatan literasi.

Mengingat pentingnya kemampuan berliterasi, pemerintah melalui Kementerian Pendidikan dan Kebudayaan menekankan kembali kepada pemerintah daerah untuk menggalakkan program membudayakan literasi dalam program Gerakan Literasi Nasional (GLN), salah satunya diimplementasikan melalui Gerakan Literasi Sekolah (GLS) yang tertuang dalam ("Peraturan Menteri Pendidikan dan Kebudayaan RI Nomor 23 Tahun 2015 tentang Penumbuhan Budi Pekerti.," n.d.). Mengacu pada Permendikbud No. 23/2015 ini, diterbitkan pula beberapa dokumen panduan gerakan literasi sekolah (GLS) yang mencakup: Desain Induk Gerakan Literasi Sekolah (2016) yang memuat platform pelaksanaan GLS di berbagai jenjang pendidikan di Indonesia mulai tingkat dasar hingga menengah atas serta Panduan Gerakan Literasi di Sekolah Dasar (2016) yang sesuai dengan layanan minimum pada pendidikan dasar di daerah. 
Program ini telah dilaksankan diantaranya (Akbar, 2017; Antasari, 2017; Ika Oktavianti, ., Eka Zuliana, 2017; Megawati \& Wulandari, n.d.; Rahayu \& Dahlan, 2016; Ranti Wulandari, 2017; Teguh, 2017; Wandasari, 2017). Namun dalam pelaksanaannya tidak semua pemangku kebijakan memahami benar tentang budaya literasi, baik di sekolah melalui GLS maupun di masyarakat melalui taman baca masyarakat (TBM). Berdasarkan hasil observasi yang dilakukan di sekolah dasar di beberapa wilayah Kota Surabaya pada tahun Maret-April 2016-kota yang telah mendeklarasikan sebagai Kota Literasi sejak tahun 2014 (Antara News., 2014). Banyak dijumpai pengelola sekolah hanya pasrah dengan instruksi gerakan literasi dari pemerintah tanpa benar-benar faham indikator keberhasilan gerakan literasi; pemahaman literasi hanya sebatas membaca dan menulis saja. Selain itu, GLS tidak diikuti dengan program literasi yang berkelanjutan, peran perpustakaan yang masih minim dan bahkan kurang maksimal karena digunakan sebagai ruang kelas reguler.

Salah satu indikasi bagaimana pelaksanaan GLS masih rendah adalah alokasi anggaran 5\% untuk pengadaan buku masih difokuskan pada pengadaan buku pelajaran; di mana masih dinilai minim kontribusi terhadap kesuksesan gerakan literasi yang menekankan pada buku bacaan non-pelajaran. Selain pelaksanaan GLS yang terbatas, peran masyarakat dan orang tua dalam menyukseskan GLS masih dinilai minim. Dalam tataran masyarakat sebagai bagian dari GLN, masyarakat dinilai masih belum memahami konsep budaya literasi dan bagaimana peran mereka dalam menyukseskan gerakan ini. Berdasarkan observasi awal, taman bacaan masyarakat (TBM) masih sepi pengunjung dan mengandalkan pada operasional pemerintah daerah, masyarakat tidak dilibatkan dalam pengadaan bahan bacaan, serta keberlanjutan TBM yang masing penuh tanda tanya.

Oleh karenanya, merujuk kembali pada deklarasi pemerintah untuk mewujudkan masyarakat yang berliterasi melalui satuan pendidikan, seyogyanya perlu menimbang kembali program GLN yang telah digalakkan oleh pemerintah dapat mencapai tujuan yang telah dicanangkan. Melalui studi sosial sekolah dasar dan masyarakat melalui program kampung literasi, penelitian deskriptif kualitatif ini difokuskan untuk mengetahui persepsi dan peran masyarakat dalam menyukseskan Gerakan Literasi Nasional (GLN). Selain itu, penelitian ini nantinya dapat memberikan rekomendasi tentang peranan masyarakat guna merevitalisasi gerakan literasi di masyarakat yang menjadi bagian dari kesuksesan GLN. Kajian terkait dengan rekomendasri revitalisasi peran masyarakat dalam menyukseskan GLN juga mencakup peran masyarakat dalam menyukseskan GLS di sekolah dasar. Penelitian ini tidak hanya terfokus pada strategi sekolah dasar (SD) dalam mengimplementasikan GLS, melainkan perpustakaan penunjang di sekitar sekolah dasar yang tak lain adalah taman bacaan masyarakat (TBM) di balai RW di sekita sekolah dasar yang menjadi bagian dari program kampung literasi. 


\section{METODE PENELITIAN}

Berdasarkan permasalahan yang menjadi fokus penelitian ini maka penelitian ini merupakan kualitatif dengan jenis penelitian studi kasus melalui pendekatan etnografis. Penelitian ini dilaksanakan di desa Tulangan, Kecamatan Tulangan, Kabupaten Sidoarjo. Kabupaten Sidoarjo sebagai wilayah penyangga Kota Surabaya juga memulai penerapan gerakan literasi di institusi pendidikan dengan mengacu program literasi di Kota Surabaya yang dianggap telah berjalan dengan cukup baik. Selain itu, di beberapa wilayah Kabupaten Sidoarjo, terdapat beberapa desa yang berinisiatif sebagai kampung literasi melalui beberapa program di antaranya taman baca masyarakat (TBM).

Pengumpulan data dilaksanakan dalam kurun waktu Maret-Mei 2018 dengan menggunakan observasi, wawancara dan dokumentasi. Peneliti terlibat secara langsung dalam pelaksanaan program kampung literasi di lokasi penelitian. Data dalam penelitian ini bersumber beberapa informan yakni pemangku kebijakan (misal: kepala desa dan perangkat pemerintah desa), pelaksana kampung literasi (masyarakat dan tokoh masyarakat), serta institusi pendidikan melalui pengurus sekolah. Peristiwa-peristiwa yang teramati oleh peneliti serta dokumen-dokumen yang berhubungan dengan fokus penelitian ini. Data dianalisis secara kualitatif dengan menemukan pola pelaksanaan serta peran setiap pemangku kebijakan serta masyarakat dalam kaitannya untuk melaksanakan gerakan literasi nasional melalui kampung literasi. Pola pada implementasi serta peran masyarakat diabstrasikan untuk menentukan rekomendasi guna merevitalisasi peran masyarakat untuk peningkatan gerakan literasi di masyarakat.

\section{HASIL DAN PEMBAHASAN}

Aspek pertama yang dilihat dari ketersediaan sumber daya pendukung kegiatan literasi di masyarakat yang meliput beberapa aspek yang merupakan modal inti dalam pelaksanaan GLN, yakni bangunan fisik atau sarana dan prasarana terkait pelaksanaan gerakan literasi, kondisi masyarakat (dalam hal ini yang bersinggungan secara langsung dalam kampung literasi di lokasi penelitian), serta bagaimana kondisi keuangan dalam melaksanakan GLN di kampung literasi tersebut. Berikut adalah hasil dari evaluasi GLN oleh penilai internal dan eksternal.

Tabel 1. Kesediaan Sumber Daya Pendukung

\begin{tabular}{lcl}
\multicolumn{1}{c}{ Aspek } & $\begin{array}{c}\text { Skor } \\
\text { rata-rata }\end{array}$ & \multicolumn{1}{c}{ Keterangan } \\
\hline $\begin{array}{l}\text { Tenaga pendukung kegiatan GLN } \\
\text { (Pokja) }\end{array}$ & 6,5 & $\begin{array}{l}\text { Pemerintah desa memiliki 2 petugas yang } \\
\text { bertanggung jawab pada perpustakaan desa } \\
\text { yang berlokasi di balai desa. Namun, } \\
\text { petugas tidak disediakan pada level TBM. }\end{array}$ \\
\hline $\begin{array}{l}\text { Dokumen pendukung untuk } \\
\text { pelaksanaan GLN (peta jalan, } \\
\text { panduan, modul, dan materi } \\
\text { pendukung) }\end{array}$ & 4,0 & Tidak ada dokumen pendukung GLN. \\
\hline $\begin{array}{l}\text { Ketersediaan sarana dan prasarana } \\
\text { Kand }\end{array}$ & 8,4 & $\begin{array}{l}\text { Di desa, terdapat 5 titik yang berpotensi } \\
\text { sebagai pendukung kampung literasi: }\end{array}$ \\
\hline
\end{tabular}




\begin{tabular}{|c|c|c|}
\hline Aspek & $\begin{array}{c}\text { Skor } \\
\text { rata-rata }\end{array}$ & Keterangan \\
\hline & & $\begin{array}{l}\text { pespustakaan desa dan } 4 \text { balai RW yang } \\
\text { tersebar di RW masing-masing. Hanya } 1 \\
\text { balai RW yang dioperasikan untuk } \\
\text { pendukung kampung literasi sebagai TBM } \\
\text { swadana oleh warga sekitar. }\end{array}$ \\
\hline Anggaran & 4,0 & $\begin{array}{l}\text { Tidak ada anggaran dari pemerintah terkait } \\
\text { pelaksanaan GLN dan kampung literasi. }\end{array}$ \\
\hline
\end{tabular}

Secara garis besar, ketersediaan sumber daya fisik pendukung GLN di kampung literasi kurang memadai. Tampak dari hasil evaluasi persepsi masyarakat, diketahui aspek bangunan fisik, dokumen, dan anggaran dirasa berada di angka di bawah rata-rata. Namun demikian, desa ini memiliki potensi yang besar apabila ada kordinasi dan kegiatan yang literatif. Adanya 5 titik yang berpotensi sebagai fasilitas pendukung kegiatan literasi berarti desa ini memiliki modal yang cukup untuk menciptakan lingkungan masyarakat yang literatif.

Dalam aspek sumber daya, pemerintah desa hanya menyediakan 2 petugas yang mengelola perpustakaan desa (di Kantor Desa) dan tidak ada kelanjutan pada tataran taman baca masyarakat. Kondisi perpustakaan desa ini memang memenuhi syarat minimal Standar Nasional Indonesia bidang perpustakaan desa/kelurahan (2011) dari segi kualifikasi pendidikan pengelola berlatar SMA, jumlah koleksi 1000 koleksi, pendanaan, serta jam operasional minimal 35 jam per minggu. Yang menjadi kendala adalah akses masyakat atas keberadaan perpustakaan desa yang terbatas di kantor desa. berbeda dengan taman baca masyarakat (TBM) yang mana justru bersinggungan langsung dengan masyarakat. Apabila diasumsikan TBM representasi perpustakaan desa, kondisinya jauh di bawah standar nasional perpustakaan desa/kelurahan tahun 2011, terutama dalam aspek pendanaan, koleksi, dan pengelolaan program perpustakaan.

Selain itu, kondisi TBM yang sudah ada dan lokasi lain yang berpotensi dapat digunakan sebagai taman baca masyarakat adalah balai RW. Ini salah satu potensi yang dimiliki kampung literasi, di mana balai RW dirasa lebih bersentuhan dan terakses oleh masyarakat daripada di kantor desa. Terdapat 4 bangunan fisik baru di masing-masing RW dengan ukuran 3x6 meter yang terdiri dari 2 bagian utama, yakni tempat terbuka dengan atap genting dan ruang tertutup berukuran 1,5x3 meter yang digunakan untuk tempat penyimpanan barang dan dokumen. Bangunan ini difasilitasi dengan aliran listrik, lantai yang bersih, pelindung panas dari bamboo rotan, dan tempat parker yang memadai. Namun demikian, dari 4 balai RW, hanya 1 balai RW 02 yang dimanfaatkan sebagai taman baca masyarakat (TBM). Balai RW lain hanya digunakan sebagai rapat warga dan ronda di malam hari.

Salah satu faktor yang membuat balai RW 02 berfungsi sebagai fasilitas pendukung kampung literasi adalah peran tokoh masyarakat, yakni Ketua Rukun Tetangga (RT). Abbas (2015) mengatakan bahwa tokoh masyarakat memiliki peran yang kuat membudayakan literasi, yakni dengan cara menyampaikan informasi terbaru kepada warga melalui rapat warga atau selebaran bila perlu. Tujuannya adalah membuat warga membaru dan tidak anti-sosial. Di lingkungan 
di mana RW 02 berada, Ketua RT bahkan mengundang warga yang memiliki latar pendidikan tinggi dan mahasiswa untuk turut aktif sebagai tutor bimbingan belajar agar adik-adik para siswa dapat belajar bersama di Balai RW 02. Sehingga terjadi pergesaran fungsi dari balai RW dari bangunan ronda dan keamanan menjadi tempat berkumpul warga.

Tabel 2 Kegiatan Masyarakat Pendukung

\begin{tabular}{lll}
\hline \multicolumn{1}{c}{ Aspek } & Skor rata-rata & \multicolumn{1}{c}{ Keterangan } \\
\hline $\begin{array}{l}\text { Rapat-rapat, DKT, } \\
\text { lokakarya, dan kegiatan lain } \\
\text { yang sejenis }\end{array}$ & 4,0 & $\begin{array}{l}\text { Tidak ada sosialisasi tentang kampung } \\
\text { literasi. Petugas desa yang menjaga } \\
\text { perpustakaan balai desa juga tidak memiliki } \\
\text { latar tentang gerakan literasi. Hanya ada } \\
\text { satu kali bimbingan teknis. }\end{array}$ \\
\hline $\begin{array}{l}\text { Pelatihan calon fasilitator } \\
\text { dan pendampingan }\end{array}$ & 5,2 & $\begin{array}{l}\text { Ketua RT melakukan pemilihan secara } \\
\text { informal tentang warga yang terlibat } \\
\text { sebagai tutor dengan kriteria pendidikan } \\
\text { minimal SMA dan/atau status mahasiswa. }\end{array}$ \\
\hline $\begin{array}{l}\text { Pemantauan pelaksanaan } \\
\text { GLN di sekolah, keluarga, } \\
\text { dan masyarakat }\end{array}$ & $\begin{array}{l}\text { Pemantauan dilakukan oleh warga secara } \\
\text { swadana selama proses bimbingan belajar di } \\
\text { malam hari. Warga yang sebelumnya } \\
\text { berkaraoke sejak sore di Balai RW 02 harus } \\
\text { menunggu bimbingan belajar selesai. }\end{array}$ \\
\hline
\end{tabular}

Secara umum, belum ada kegiatan khas sebagai penggerak masyarakat pada gerakan literasi nasional (GLN) di kampung literasi. Salah satu upaya yang harus dilakukan masyarakat dalam kaitannya dengan gerakan literasi adalah keberlanjutana, dan hal ini perlu dimulai dengan adanya kegiatan yang literatif. Minimnya sosialisasi dan pembinaan teknis tentang GLN tampaknya menjadi faktor yang membuat masyarakat masih enggan dalam berinisiatif melakukan kegiatan yang bersifat literatif. Oleh karena tidak mengherankan apabila tidak ada kegiatan kordinasi, rapat, bahkan fasilitator yang turn lapangan secara langsung berbicara literasi. Padahal, langkah pertama yang perlu dilakukan agar masyarakat memiliki pengetahuan tentang literasi adalah melalui sosialisasi.

Sebagai upaya untuk menjaga kegiatan yang dapat dijadikan induk gerakan literasi adalah belajar kelompok para siswa di lingkungan masyarakat. Kegiatan ini sebagai alternatif atas bimbingan belajar. Pada saat yang sama, secara swadana dengan dorongan tokoh masyarakat, masyarakat sebenarnya bersedia terlibat dalam membudayakan literasi melalui kelompok belajar di masing-masing TBM di lingkunga masyarakat. Masyarakat di RW 02 memiliki aktivitas belajar bersama di sore hari di mana tutornya dari warga sendiri secara mandiri (dengan latar pendidikan SMA). Warga lainnya yang tidak terlibat sebagai tutor turut hadir guna mengawasi serta memberikan dukungan moral agar kegiatan dapat berjalan secara guyub. Selain itu, kehadiran warga juga sebagai langka huntuk memantau sebarapa jauh masyarakat memiliki kesadaran tentang budaya literasi.

Selama penelitian ini dilakukan dalam kurun waktu dua bulan, terdapat beberapa capaian yang tampak di masyarakat sebagai bagian dari kampung 
literasi. Capaian-capaian ini nanti dapat dijadikan sebagai potensi pengembangan program literatif di masyarakat, di antaranya:

Tabel 3 Luaran dan Hasil Kegiatan

\begin{tabular}{lcc}
\hline \multicolumn{1}{c}{ Aspek } & Skor rata-rata & \multicolumn{1}{c}{ Keterangan } \\
\hline $\begin{array}{l}\text { Perkembangan capaian GLN di } \\
\text { sekolah, keluarga, dan } \\
\text { masyarakat }\end{array}$ & 8,2 & $-\begin{array}{l}\text { Peran perpustakaan di SD } \\
\text { lebih baik dengan adanya } \\
\text { kode warna }\end{array}$ \\
& & $-\quad \begin{array}{l}\text { Warga memiliki TBM } \\
\text { mandiri di 1 balai RW }\end{array}$ \\
& & $-\quad \begin{array}{l}\text { Warga memiliki kelompok } \\
\text { belajar mandiri di balai RW }\end{array}$ \\
\hline $\begin{array}{l}\text { Analisis hasil capaian untuk } \\
\text { perbaikan program GLN }\end{array}$ & & $\begin{array}{l}\text { Masih terpusat di (perpustakaan) } \\
\text { sekolah dan RW 02. Namun kedua } \\
\text { tempat ini dapat dijadikan sebagai } \\
\text { model untuk pengembangan di lokasi } \\
\text { yang lain. }\end{array}$ \\
\hline
\end{tabular}

Sistem kode buku sangat membantu dalam memberikan akses kepada masyarakat untuk mencari bahan bacaan yang sesuai. Alih-alih menggunakan angka dan huruf pada umumnya, pengodean buku dilengkapi dengan metode warna untuk memudahkan anak-anak tingkat bawah (sekolah dasar) mengetahui jenis buku yang hendak mereka baca. Pengodean ini diadopsi dari sistem yang dilaksanakan di perpustakaan sekolah dasar (yang digagas oleh kegiatan kuliah kerja nyata $(\mathrm{KKN})$ mahasiswa). Salah satu hal yang diturunkan dari perpustakaan sekolah yakni koleksi bacaan di TBM yang difokuskan pada bacaan non-sekolah; di perpustakaan sekolah, kebijakan pengadaan buku perpustakaan yang masih didominasi buku bacaan sekolah, bukan buku non-sekolah atau bacaan sastra dan umum. Hal ini nantinya kurang memberikan pilihan dan kesempatan bagi siswa terhadap kegiatan membaca untuk kesenangan (reading for pleasure), bukan membaca untuk tagihan (sekolah).

Selain itu, capaian yang patut diapresiasi adalah bagaimana warga RW 02 dapat bersama mengoptimalkan peran Balai RW 02 sebagai pusat berkumpul. Sekalipun koleksi buku bacaan di TBM RW 02 hanya berkisar 240 eksamplar, namun ini adalah langkah yang bagus dalam dua bulan. Hal ini membuktikan bahwa arahan tokoh masyarakat dan warga yang kompak akan memberikan capaian yang nyata dalam membudayakan literasi.

Mengukur dampak pelaksanaan GLN di kampung literasi seyogyanya secara berkala dan dalam waktu yang cukup lama. Sementara pelaksanaan GLN di Desa Tulangan masih berjalan 4 bulan ( 2 bulan observasi), maka dampak secara makro belum tampak secara signifikan.

Tabel 4 Perubahan yang Tampak di Masyarakat

\begin{tabular}{|c|c|c|}
\hline Aspek & Skor rata-rata & Keterangan \\
\hline $\begin{array}{l}\text { Dampak terhadap budaya } \\
\text { literasi di tngkat }\end{array}$ & 6,2 & $\begin{array}{l}\text { - } \quad \text { Peran perpustakaan desa yang berada di } \\
\text { balai desa tidak bisa dirasakan dan }\end{array}$ \\
\hline
\end{tabular}




\begin{tabular}{lll}
\hline \multicolumn{1}{c}{ Aspek } & Skor rata-rata & \multicolumn{1}{c}{ Keterangan } \\
\hline $\begin{array}{l}\text { sekolah,keluarga, dan } \\
\text { masyarakat }\end{array}$ & $-\begin{array}{l}\text { diakses oleh semua warga. } \\
\text { Warga bersedia terlibat dalam kegiatan } \\
\text { tutor kelompok belajar. }\end{array}$ \\
& $-\begin{array}{l}\text { Warga mengubah fungsi balai RW } \\
\text { menjadi TBM. }\end{array}$ \\
\hline $\begin{array}{l}\text { Dampak secara makro } \\
\text { terhadap indikator- } \\
\text { indikator literasi di tingkat } \\
\text { nasional }\end{array}$ & - & \\
\hline
\end{tabular}

Dampak dari kampung literasi dalam dua bulan pertama masih dirasa parsial sehingga belum mencapai dampak secara makro terhadap GLN secara global. Namun demikian, hal ini dapat dijadikan refleksi bagi pemangku kebijakan terhadap implementasi GLN di kampung literasi, di antaranya bagaimana akses bacaan bagi masyarakat perlu dikembangkan dan dipermudah. Selain itu, perhatian pemerintah desa harus dimaksimalkan terutama bagi lokasi lain yang masih belum bisa mengubah peran balai RW sebagai TBM. Hal ini berkaitan dengan prioritas distribusi akses masyarakat atas bahan bacaan yang selama ini hanya terpusat di balai desa, digeser pada balai RW yang mana lebih bersinggungan langsung dengan masyarakat.

Berdasarkan hasil dari persepsi masyarakat, terdapat beberapa langkah untuk memaksimalkan peran masyarakat guna merevitalisasi masyarakat dalam GLN di kampung literasi.

\section{Tabel 5 Revitalisasi Peran Masyarakat terhadap Gerakan Literasi Nasional di Kampung Literasi}

\begin{tabular}{|c|c|c|}
\hline Aspek & Skor Rata-Rata & Revitalisasi \\
\hline $\begin{array}{l}\text { Tenaga pendukung } \\
\text { kegiatan GLN (Pokja) }\end{array}$ & 6,5 & 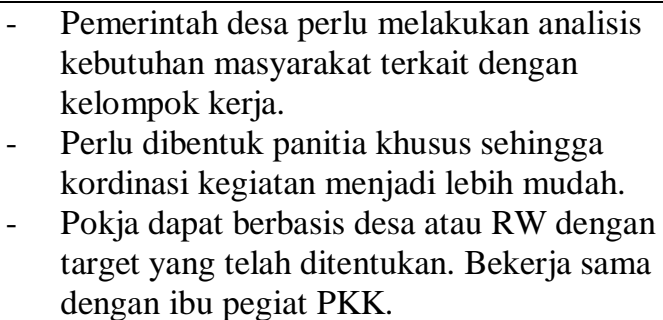 \\
\hline
\end{tabular}

\begin{tabular}{|c|c|c|}
\hline $\begin{array}{l}\text { Dokumen pendukung } \\
\text { untuk pelaksanaan } \\
\text { GLN (peta jalan, } \\
\text { panduan, modul, dan } \\
\text { materi pendukung) }\end{array}$ & 4,0 & $\begin{array}{l}\text { Desa dapat bekerja sama dengan desa lain yang } \\
\text { memiliki program yang sama, terkait kordinasi } \\
\text { dengan Badan Perpustakaan Daerah guna } \\
\text { pelengkapan dokumen pendukung GLN. }\end{array}$ \\
\hline $\begin{array}{l}\text { Ketersediaan sarana } \\
\text { dan prasarana }\end{array}$ & 8,4 & $\begin{array}{l}\text { - Pemerintah desa perlu membuat aturan terkait } \\
\text { fungsi dan peran balai RW sebagai pusat } \\
\text { literasi dalam bentuk taman baca masyarakat } \\
\text { (TBM). } \\
\text { - Pemerintah desa perlu mengadaptasi program } \\
\text { sejenis yang sukses sebagaimana di Kota }\end{array}$ \\
\hline
\end{tabular}




\begin{tabular}{ll}
\hline Aspek & \multicolumn{1}{c}{ Revitalisasi } \\
\hline & Surabaya. \\
& Pelengkapan fasilitas dan sarana pendukung \\
& agar fungsi balai RW sebagai TBM dapat \\
& terealisasi (misal: rak buku, alat kebersihan, \\
& koneksi internet, dsb.). Semua hal itu pada \\
& dasarnya telah menjadi aturan pemerintah \\
& terkait dana desa.
\end{tabular}

Merujuk pada UU No. 43/2007 tentang alokasi Dana Desa dan Permendes 22/2016 tentang prioritas penyediaan perpustakaan di setiap jenjang pemerintahan.

\begin{tabular}{|c|c|c|}
\hline Anggaran & 4,0 & 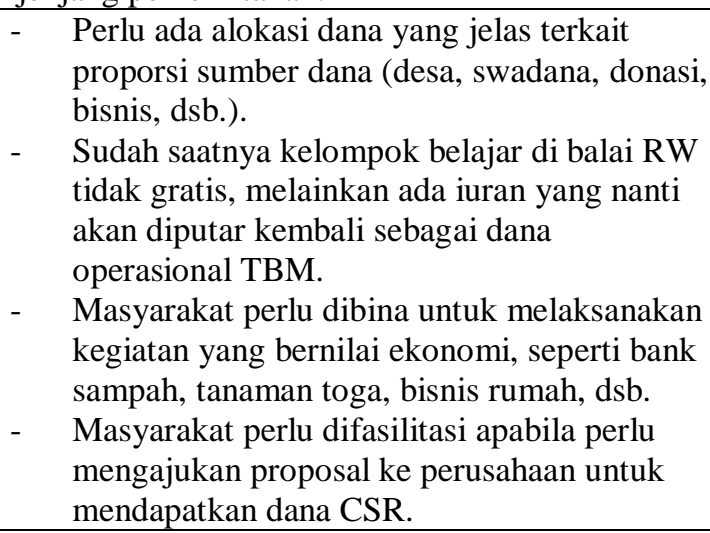 \\
\hline $\begin{array}{l}\text { Rapat-rapat, DKT, lokakarya, } \\
\text { dan kegiatan lain yang sejenis }\end{array}$ & 4,0 & 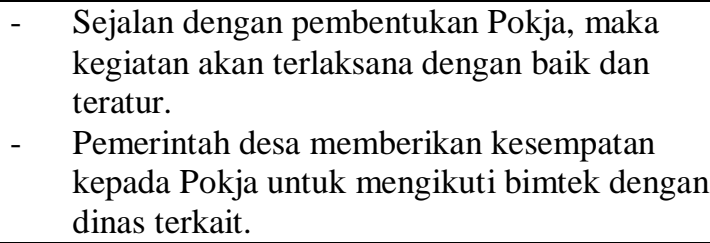 \\
\hline $\begin{array}{l}\text { Pelatihan calon fasilitator dan } \\
\text { pendampingan }\end{array}$ & 5,2 & $\begin{array}{l}\text { - Apabila sebelumnya tutor dan pendamping } \\
\text { literasi masih swadana berdasarkan latar } \\
\text { pendidikan, perlu untuk ikut serta pada } \\
\text { pelatihan dan bimtek dari dinas terkait. } \\
\text { - Mengundang tokoh pengelolaan TBM atau } \\
\text { pegiat literasi untuk berbagi ide dan gagasan. }\end{array}$ \\
\hline $\begin{array}{l}\text { Pemantauan pelaksanaan GLN } \\
\text { di sekolah, keluarga, dan } \\
\text { masyarakat }\end{array}$ & 6,2 & $\begin{array}{l}\text { - Pemantauan seharusnya dilakukan baik dari } \\
\text { pihak internal (desa dan masyarakat) serta } \\
\text { eksternal yakni oleh LSM atau akademisi. } \\
\text { - Pemantauan dilakukan secara rutin dan } \\
\text { berkala. }\end{array}$ \\
\hline $\begin{array}{l}\text { Perkembangan capaian GLN } \\
\text { di sekolah, keluarga, dan }\end{array}$ & 8,2 & $\begin{array}{l}\text { Minimal 5\% dana BOS harus dibelanjakan untuk } \\
\text { pengadaan buku bacaan non-sekolah. }\end{array}$ \\
\hline
\end{tabular}
masyarakat

\begin{tabular}{|c|c|c|}
\hline $\begin{array}{l}\text { Analisis hasil capaian untuk } \\
\text { perbaikan program GLN }\end{array}$ & 6,2 & 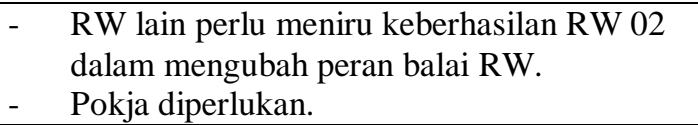 \\
\hline $\begin{array}{l}\text { Dampak terhadap budaya } \\
\text { literasi di tngkat } \\
\text { sekolah,keluarga, dan } \\
\text { masyarakat }\end{array}$ & 6,2 & $\begin{array}{l}\text { - } \\
\text { TBM akan lebih efektif daripada } \\
\text { perpustakaan di balai desa. } \\
\text { - Ada solusi lain untuk keberadaan } \\
\text { perpustakaan desa, yakni dengan rak berjalan }\end{array}$ \\
\hline
\end{tabular}




\begin{tabular}{ll}
\hline \multicolumn{1}{c}{ Aspek } & \multicolumn{1}{c}{ Revitalisasi } \\
\hline terhadap indikator-indikator & budaya literasi di kampung literasi dapat \\
lilterasi di tngkat nasional & didengar dan ditiru oleh khalayak dari tempat \\
& lain. \\
& $-\begin{array}{l}\text { Pergunakan peran media sosial dan media } \\
\text { masaa. }\end{array}$ \\
\hline
\end{tabular}

Secara teknis, revitalisasi dapat dilaksanakan melalui pemaksilan dukungan dari pemerintah desa dan inisiatif masyarakat atas capaian yang sudah ada dan potensi yang dimiliki. Secara konseptual, misalnya, literasi bertumpu pada konsep kegiatan membaca tanpa adanya tagihan, di mana puncaknya ada pada persepsi masyarakat bahwa membaca adalah kebutuhan daripada kewajiban. Masyarakat dapat menentukan bahan bacaan yang mereka inginkan sesuai dengan tingkat kognitif masing-masing tanpa beban tugas dan tagihan atau pertanyaan yang harus dijawab, dan bahkan tanpa keharusan untuk menyelesaikan buku tersebut bila buku itu membosankan atau terlalu sulit. Krashen (2004) menyatakan bahwa ada banyak bukti hasil penelitian yang menunjukkan bahwa membaca mandiri memberikan kontribusi terhadap perkembangan bahasa dan literasi.

Secara sosial sebagai upaya revitalisasi masyarakat adalah, bahwa adanya upaya untuk menginternalisasi budaya literasi pada tataran individu. Bahwa individu harus memiliki rasa tanggung jawab masing-masing sebagai anggota masyarakat. Dalam struktur masyarakat kampung, yang memainkan peran lebih signifikan yakni tokoh masyarakat bukan pemerintah (desa). Secara struktur sosial, tokoh masyarakat ini menjadi model sekaligus kotrol proses sosialisasi antar masyarakat sebagai proses difusi internalisasi literasi. Tokoh masyarakat dipercaya memiliki peran kontrol sosial bagaimana masyarakat dapat memiliki kemampuan berliterasi serta menerapkannya dalam kehidupan sehari-hari (Pamungkas, 2017).

\section{KESIMPULAN DAN SARAN}

Berdasarkan temuan dan pembahasan serta rekomendasi sebagai upaya untuk revitalisasi gerakan literasi di kampung literasi, beberapa kesimpulan seperti persepsi masyarakat terhadap gerakan literasi nasional (GLN) di kampung literasi masih di bawah rata-rata berdasarkan aspek-aspek evaluasi GLN. Beberapa hal yang perlu digaris bawahi adalah (1) peran pemerintah desa dalam memberikan sumber daya fisik dan manusia. Sementara sumber daya fisik sudah terpenuhi, pemerintah desa perlu melakukan optimalisasi sumber daya manusia seperti kelompok kerja atau panitia, fasilitator, serta keikutsertaan ibu-ibu pegiat PKK dan warga secara umum. (2) kegiatan yang menunjang GLN dirasa masih minim karena tidak adanya pokja yang khusus menangani GLN di kampung literasi. Berkaitan dengan kondisi ini, masyarakat perlu diberdayakan untuk swadana dalam melakukan kegiatan literatif daripada bergantung sepenuhnya pada pemerintah desa karena proses literasi pada dasarnya adalah inisiatif individu yang menjadi bagian dari masyarakat. (3) selama proses pelaksanaannya, hanya 1 dari 4 RW yang sudah memulai kampong literasi dengan mengubah peran balai RW menjadi pusat literasi dan TBM. Merujuk pada akses bacaan, dalam hal ini 
pemerintah desa seharusnya mengubah konsep perpustakaan desa di kantor desa didistribusikan menjadi perpustakaan masyarakat (TBM) yang berada di balai RW karena lebih bersinggungan langsung dengan masyarakat.

\section{DAFTAR RUJUKAN}

Abbas. (2015). Community Participation in Education: Challenges and Prospects in Nigeria's Democracy. Eur. Sci. J., 8(5), 1-11.

Akbar, A. (2017). MEMBUDAYAKAN LITERASI DENGAN PROGRAM 6M DI SEKOLAH DASAR. JPSD (Jurnal Pendidikan Sekolah Dasar), 3(1).

Antara News. (2014). Surabaya Deklarasikan sebagai Kota Literasi. 2. Retrieved from www.antaranews.com/berita/432307/surabaya-deklarasikan-sebagaikota-literasi

Antasari, I. W. (2017). Implementasi Gerakan Literasi Sekolah Tahap Pembiasaan di MI Muhammadiyah Gandatapa Sumbang Banyumas. LIBRIA, 9(1), 1326.

Ika Oktavianti, ., Eka Zuliana, Y. R. (2017). Menggagas kajian kearifan budaya lokal di sekolah dasar melalui gerakan literasi sekolah. Prosiding Seminar Nasional, (March).

Krashen, S. D. (2004). The Power of Reading: Insights from the Research, 2nd Edition: Insights from the Research. Portsmouth: Library Unlimited Reed Elsevier, Inc.

Megawati, F., \& Wulandari, F. (n.d.). PROMOTING BIG BOOK AND READING CORNER TO SUPPORT. Prosiding Seminar Nasional Pendidikan: Tema "DESAIN PEMBELAJARAN DI ERA ASEAN ECONOMIC COMMUNITY (AEC) UNTUK PENDIDIKAN INDONESIA BERKEMAJUAN" Fakultas Keguruan Dan Ilmu Pendidikan Universitas Muhammadiyah Sidoarjo, 11-19.

OECD. (2014). PISA 2012 Results in Focus: What 15-year-olds Know and What They Can Do with What They Know.

Pamungkas, A. H. (2017). Role of Community Leaders in Efforts to Preserve Literacy Tradition. Advances in Social Science, Education and Humanities Research. Atlantis Press, 118.

Pahl \& Rowsell. 2005. Literacy and Education: Understanding the New Literacy Studies in the Classroom. London: SAGE Publications.

Peraturan Menteri Pendidikan dan Kebudayaan RI Nomor 23 Tahun 2013 tentang StandarPelayananMinimalPendidikanDasar di Kabupaten/Kota.

PeraturanMenteri

Peraturan Menteri Pendidikan dan Kebudayaan RI Nomor 23 Tahun 2015 tentang Penumbuhan Budi Pekerti. (n.d.).

Perpustakaan Nasional RI. 2011. Standar Nasional Indonesia Bidang Perpustakaan dan Kepustakawanan. Jakarta: Perpustakaan Nasional RI.

Rahayu, T., \& Dahlan, U. A. (2016). Penumbuhan budi pekerti melalui gerakan literasi sekolah. The Progressive and Fun Education Seminar, 179-183.

Ranti Wulandari. (2017). IMPLEMENTASI KEBIJAKAN GERAKAN LITERASI SEKOLAH DI SEKOLAH. Jurnal Kebijakan Pendidikan Edisi 
3 Vol.VI Tahun 2017, VI(3), 319-330.

Teguh, M. (2017). Gerakan literasi sekolah dasar. PROSIDING SEMINAR NASIONAL 15 MARET 2017, 18-26.

UNESCO. (2003). The Prague Declaration. "Towards an Information Literate Society."

Wandasari, Y. (2017). IMPLEMENTASI GERAKAN LITERASI SEKOLAH (GLS) SEBAGAI PEMBENTUK PENDIDIKAN BERKARAKTER. Jurnal Manajemen, Kepemimpinan, Dan Supervisi Pendidikan, 1(1), 325-343. 